\title{
The Effect of the Cooling Rate on the Microstructure and Microsegregation: An Experimental and Numerical Investigation of Solidification in Hypoperitectic Cu - 20 wt.\% Sn Alloy
}

\author{
Késsia Gomes Paradela ${ }^{a}$,Wysllan Jefferson Lima Garção ${ }^{a, b}$, Luis Antônio de Souza Baptista ${ }^{a}$, \\ Roberto Carlos Sales ${ }^{a}$, Vânia Cristina de Oliveira ${ }^{a}$, Alexandre Furtado Ferreira ${ }^{{ }^{*}}$ (i) \\ ${ }^{a}$ Universidade Federal Fluminense, Programa de Pós-Graduação em Engenharia Metalúrgica, \\ Volta Redonda, RJ, Brasil \\ ${ }^{b}$ Instituto Federal do Rio de Janeiro, Campus Volta Redonda, Volta Redonda, RJ, Brasil
}

Received: March 20, 2020; Revised: June 17, 2020; Accepted: June 18, 2020

\begin{abstract}
Hypoperitectic $\mathrm{Cu}-20 \mathrm{wt}$ \% $\mathrm{Sn}$ alloy was solidified under different cooling rates and solidification growths using directional solidification system. The effects of cooling rate and solidification growth on the microsegregation profiles and tertiary dendritic arm spacing $\left(\lambda_{3}\right)$ were experimentally investigated along the casting. A mathematical model known as phase-field was applied to simulate microstructure and microsegregation during solidification in system $\mathrm{Cu}-\mathrm{Sn}$ liquid. In this paper the applicability of the phase-field model to the solidification problem in a real alloy system was systematically explored. Microsegregation profiles and realistic dendritic structures were obtained using the phase-field model. The results calculated by phase-field model show various solidification features consistent with our experiment. The calculated tertiary dendritic arm spacing $\left(\lambda_{3}\right)$ and microsegregation profiles were compared with experimental values from directional solidification system. Since the calculated microsegregation profiles using the equilibrium partition coefficient $\left(\boldsymbol{k}_{e q}\right)$ can yielded discrepancies from the experimental results, an effective partition coefficient $\left(\boldsymbol{k}_{e f}\right)$ as a function of solidification growth, is proposed in phase-field model, showing a good agreement with the experimental data for any case examined.
\end{abstract}

Keywords: Cu-Sn alloy, solidification, dendritic microstructure, microsegregation, phase-field model.

\section{Introduction}

From seminal experimental studies on alloys solidification using unidirectional solidification process, dating back to the early 1980's, a collection of experimental works has stemmed ever since, in order to investigate the microstructural growth during the solidification process ${ }^{1-11}$. This technique allows the study of the solid phase growth as a function of thermal variables and solidification growth, making it a very attractive technique for investigations on solidification process in alloys of eutectic or near-eutectic composition ${ }^{12-14}$. Metal alloys of copper, especially bronze, are one of the first metallic materials used by mankind. The $\mathrm{Cu}-\mathrm{Sn}$ alloys has good anti-fretting characteristics and corrosion resistance for practical use. Although of the good characteristics of $\mathrm{Cu}-\mathrm{Sn}$ alloys; works focused on the importance of process variables of solidification on the microsegregation and resulting microstructure still is scarce in the literature ${ }^{15-18}$. The influence of cooling rate on the intermetallic phase $\left(\mathrm{Cu}_{6} \mathrm{Sn}_{5}\right)$ formation in the $\mathrm{Cu}-\mathrm{Sn}$ alloys, distribution and microstructure were studied by Mardare and Hassel ${ }^{15}$. The micrographs have shown both particle size and distribution in the $\mathrm{Cu}-\mathrm{Sn}$ alloy, as a function of cooling rate. One can see that particle size increased as the cooling rate decreased and for samples cooled under low solidification growth a needle structure perpendicular to the solidification front is found. The rapid

*e-mail: alexandrefurtado@id.uff.br solidification of ternary alloy $(\mathrm{Cu}-\mathrm{Sn}-\mathrm{Sb})$ was realized by Zhai et al. ${ }^{16}$. The constitution of ternary alloy in these rapid solidification experiments proposed by Zhai et al. ${ }^{16}$, deviates from the equilibrium phases. The solidification microstructure is characterized by lamellar structure, based on inner strips of primary phase $\varepsilon\left(\mathrm{Cu}_{3} \mathrm{Sn}\right)$, the intermediate layer of $\eta\left(\mathrm{Cu}_{6} \mathrm{Sn}_{5}\right)$, and the outer layer $\beta(\mathrm{SnSb})$. Kazuhiro et al. ${ }^{17}$ have studied the effect of $\mathrm{Ca}$ addition on solidification structure and mechanical response in ternary system $(\mathrm{Cu}-\mathrm{Sn}-\mathrm{Zn})$. Furthermore, in that work the effect of cooling rate on the segregation of solute was experimentally investigated. The $\mathrm{Ca}$ addition favored a decrease in micro shrinkage cavity and formation of microstructures refined. The systems $\mathrm{Cu}$ and $\mathrm{Cu}-\mathrm{Sn}$ have been chosen by Battersby et al. ${ }^{18}$, to study the effect of solidification growth and super-cooling on solidification structure. In pure metal $(\mathrm{Cu})$, the super-cooling has been shown to not affect appreciably the solidification growth and size grain. However, experimental results obtained by Battersby et al. ${ }^{18}$ indicate that, at the high super-cooling, finer microstructure was observed. Microstructural analysis and microhardness measurements indicate that the recrystallisation accompanies the grain refinement in $\mathrm{Cu}-\mathrm{Sn}$ systems. In the last decades, appreciable attention has been paid, in the open literature, to the modeling and simulation by the phase-field model of solidification process and related phenomena ${ }^{19-30}$. Many different modeling approaches have been proposed 
to that end. Some numerical works have focused on pure materials, whereas others took heed of alloys of manufacturing interest. One example is the numerical work proposed by Ferreira et al. ${ }^{19}$, which applies the phase-field model to such problems. In that paper, the authors used phase-field model to simulate the solidification process for pure material (nickel) and the numerical results have been compared with solidification theory and experimental data reported in the literature. Numerical results have been published pertaining to phase-field modeling focused on microsegregation in ternary alloys by Wynblatt and Landa ${ }^{20}$ and Ferreira and Olivé $^{21}$. On the other hand, some numerical works has been performed on microsegregation and microstructure evolution in multicomponent alloys, Salvino et al. ${ }^{22,23}$. Phase-field models are known to be very powerful in describing non-equilibrium dendritic evolution. These models are very efficient especially in numerical treatment due all governing equations are written in unified forms without distinguishing the interface from solid and liquid phases. Direct tracking of the solid/liquid interface is not needed during solidification process simulation. The computational domain is represented by a distribution of the single variable known as "phase-field variable". It is in this general framework that the present work is developed, a numerical investigation by phase-field model with focus on solidification process in hypoperitectic $\mathrm{Cu}-\mathrm{Sn}$ alloy. Directional solidification experiment on $\mathrm{Cu}-\mathrm{Sn}$ alloy have been conducted at high solidification growth in a water-cooled solidification setup.

\section{Phase-field Modeling}

In phase-field models, the state of the domain is customarily represented by a distribution of the single variable known as the "phase-field variable", in this present paper represented by the Greek letter $\phi$. The value $\phi=+1$ is associated with solid phase, $\phi=0$ corresponds to the liquid and between 0 and +1 indicates the solid/liquid interface. For simulation of solidification microstructure in binary alloy, we used two governing equations: one for phase field itself, the other for $\boldsymbol{S} \boldsymbol{n}$ concentration. The equations can be written as proposed by Salvino et al. ${ }^{23}$ and Ode et al. ${ }^{27}$ :

$$
\begin{aligned}
& \left(\frac{1}{M}\right)\left(\frac{\partial \phi}{\partial t}\right)=\nabla \cdot a(\grave{e})^{2} \nabla \phi-w g^{\prime}(\phi)+\frac{R T}{V_{m}} h^{\prime}(\phi) \ln \frac{\left(1-c_{s}^{e q}\right)\left(1-c_{l}\right)}{\left(1-c_{l}^{e q}\right)\left(1-c_{s}\right)}+\text { noise } \\
& \frac{\partial c}{\partial t}=\nabla\left\{D(\phi)\left[(1-h(\phi))\left(1-c_{l}\right) c_{l}+h(\phi)\left(1-c_{s}\right) c_{s}\right] \nabla \ln \left(\frac{c_{l}}{1-c_{l}}\right)\right\}
\end{aligned}
$$

$\partial \phi / \partial t$ represents the evolution of the solid nucleus with time. $h(\phi)=\phi^{2}(3-2 \phi), g(\phi)=\phi^{2}(1-\phi)^{2}$, and the subscripts $s$ and $\boldsymbol{l}$ stand for solid and liquid, respectively. $R$ is the gas constant and $\boldsymbol{V}_{\boldsymbol{m}}$ the molar volume and $\boldsymbol{T}$ is the temperature. $\boldsymbol{M}, \boldsymbol{w}$ and $\varepsilon(\theta)$ are phase-field parameters; $\boldsymbol{D}(\boldsymbol{\phi})$ is the $\boldsymbol{S} \boldsymbol{n}$ diffusion coefficient. These phase-field parameters are related to the interface energy $(\sigma)$, whereas the interface width $(2 \lambda)$ is the distance where $\phi$ changes from 0.1 to 0.9 . The parameter $\boldsymbol{M}$ is related to the kinetic coefficient $(\beta)$. From Refs. ${ }^{21,30}$, these are obtained as

$$
\sigma=\frac{\varepsilon \sqrt{w}}{3 \sqrt{2}}
$$

$$
\begin{gathered}
2 \lambda=2.2 \sqrt{2} \frac{\varepsilon}{\sqrt{w}} \\
\beta=\frac{V_{m}}{R T} \frac{m_{e}}{1-k_{e f}}\left(\frac{\sigma}{M \varepsilon^{2}}-\frac{\varepsilon}{D_{i} \sqrt{2 w}} \xi\left(c_{s}^{e q}, c_{l}^{e q}\right)\right) \\
\xi\left(c_{s}^{e q}, c_{l}^{e q}\right)=\frac{R T}{V_{m}}\left(c_{l}^{e q}-c_{s}^{e q}\right)^{2} \times \int_{0}^{l} \frac{h(\phi)[1-h(\phi)]}{[1-h(\phi)] c_{l}^{e q}\left(1-c_{l}^{e q}\right)+h(\phi) c_{s}^{e q}\left(1-c_{s}^{e q}\right)} \frac{d(\phi)}{\phi(1-\phi)}
\end{gathered}
$$

where $\boldsymbol{m}_{e}$ is the slope of liquidus line, $\boldsymbol{k}_{e f}$ is the effective partition coefficient, which is calculated as a function of solidification growth $\left(\boldsymbol{S}_{G}\right)\left(k_{e f}=f\left(S_{G}\right)\right)$. The kinetic coefficient, $\beta$, is defined to be the inverse of the linear kinetic coefficient, $\mu_{k}$. Equations 1 and 2 were solved numerically by explicit finite-difference and discretized on uniform grids. The anisotropy is introduced in the phase-field model as follows, Salvino et al. ${ }^{23}$ and Kim et al. ${ }^{28}$ :

$$
\varepsilon(\theta)=\varepsilon\left\{1+\delta_{\varepsilon}\left[j\left(\theta-\theta_{0}\right)\right]\right\}
$$

where $\delta_{\varepsilon}$ gauges the anisotropy. The value $\boldsymbol{j}$ controls the number of preferential growth directions. Orientation of the maximum-anisotropy is determined by the $\theta_{0}$ constant, with $\theta$ being the angle between the direction of the phase-field gradient and the references axis of the system. Asymmetrical microstructures are obtained in the phase-field simulations by a noise term on the right-hand side of Equation 1, a usual expression for this noise, as indicated by Ferreira and Olivé ${ }^{21}$ is

$$
\text { noise }=16 \operatorname{ar}^{2}(1-\phi)^{2}
$$

where $\boldsymbol{r}$ is a random number between -1 and +1 . The " $\boldsymbol{a}$ " parameters is the noise amplitude. The physical properties of the $\mathrm{Cu}-\mathrm{Sn}$ alloy used during the computations can be found in the Refs. ${ }^{31,32}$. The parameters used in the phase-field simulations were calculated from physical properties of the $\mathrm{Cu}-\mathrm{Sn}$ alloy, Equations 3 to 6. Simulations are carried out, imposing the following linear temperature profile:

$$
T=T_{0}-\dot{T} . t
$$

where $\boldsymbol{T}_{0}$ is the initial temperature, $\dot{\boldsymbol{T}}$ represents the cooling rate and $\boldsymbol{t}$ is the solidification time. The equilibrium partition coefficient $\left(\boldsymbol{k}_{\boldsymbol{e q}}\right)$ has been replaced by an effective partition coefficient into the phase-field model, Equation 5. Burton et al. ${ }^{33}$ proposes the following equation for $\boldsymbol{k}_{e f}$

$$
k_{e f}=\frac{k_{e q}}{k_{e q}+\left(1-k_{e q}\right) e^{\left(-\frac{S_{G} \delta}{D_{l}}\right)}}
$$

$\delta$ is the diffusion layer thickness of the segregated solute ahead the solid/liquid interface and $\boldsymbol{D}_{\boldsymbol{l}}$ is the solute diffusivity in liquid region. The $\delta$ depends on the solidification growth $\left(\boldsymbol{S}_{G}\right)$, the liquid viscosity and agitation conditions ahead the solid/liquid interface, and its value can vary from $10^{-6}$ to $10^{-3} \mathrm{~m}$, according to the Chalmers ${ }^{34}$.

\section{Experimental Procedure}

Directional solidification has been widely used to produce uniform structures and to allow better control of the solidification $^{1-13}$. In this paper, a unidirectional solidification 
apparatus is adopted, which heat is extracted from bottom of mold by water cooling system. The apparatus is detailed in previous articles ${ }^{5,12}$. The upward solidification system gives more stability in liquid region since it does not induce convection currents during solidification process. In the upward vertical solidification, the solute concentration in the mushy zone and in the overlying melt ahead of the dendritic array is expected to be stable because solute enrichment causes an increase in the melt density ${ }^{12}$. The experimental cooling curves allowed to determine the thermal parameters, such as: cooling rate $(\stackrel{\ddot{y}}{\boldsymbol{T}})$ and solidification growth $\left(\boldsymbol{S}_{G}\right)$. An Optical Microscope was used to produce digital images that were analyzed using Goitaca image processing software in order to measure the tertiary dendritic arm spacing $\left(\lambda_{3}\right)$. The microsegregation measurements were taken with a scanning electron microscope JEOL for different cooling rate and positions along casting. The effect of the non-equilibrium solidification was incorporated by solidification growth $\left(\boldsymbol{S}_{G}\right)$ into an effective partition coefficient $\left(\boldsymbol{k}_{\text {ef }}\right)$ that has been calculated for a range of solidification growth from $0.88-0.96 \mathrm{~mm} / \mathrm{s}$. The solidification growth $\left(\boldsymbol{S}_{G}\right)$, tertiary dendritic arm spacing $\left(\lambda_{3}\right)$ and microsegregation profiles predicted by phase-field model, using the new partition coefficient, were compared with experimental data from hypoperitectic $\mathrm{Cu}-20 \mathrm{wt} . \% \mathrm{Sn}$ alloy. The alloy studied was produced from copper $(99.80 \%$ $\mathrm{Cu})$ and tin $(99.85 \% \mathrm{Sn})$ in a muffle furnace. The chemical composition of the alloy has been measured using X-ray fluorescence spectrometry. The temperature mapping during solidification of the $\mathrm{Cu}-20 \mathrm{wt} . \% \mathrm{Sn}$ alloy, was made using thermocouples positioned at the three different points located at 5 , 10 and $15 \mathrm{~mm}$ from the refrigerated base. The thermocouples are of the " $\mathrm{K}$ " type, with stainless steel jacket, $1.3 \mathrm{~mm}$ in diameter and protected by two layers of refractory paint. These thermocouples were connected to a high-speed data logger and, therefore, able to generate the required real time thermal profiles. The casting with height of $60 \mathrm{~mm}$, was cut for the macrostructural and microstructural analysis. After the solidification experiment, casting was sectioned along its vertical axis, and mechanically polished with abrasive papers and subsequently etched with an acid solution (Ethanol, Ferric chloride and Hydrochloric acid) during $15 \mathrm{~s}$ in order to reveal the macrostructure, Paradela et $a .^{35}$. After the macrostructural analysis, selected cross section of the solidified specimens at 5,10 and $15 \mathrm{~mm}$ from the mold bottom were polished and etched with a solution of ammonium hydroxide and hydrogen peroxide during $5 \mathrm{~s}$ and then etched with an acid solution (Ethanol, Ferric chloride and Hydrochloric acid) during $3 \mathrm{~s}$ for micrograph examination. The tertiary dendritic spacing $\left(\lambda_{3}\right)$ were measured on the cross section by averaging the distance between adjacent side branches. Dendritic spacing usually refers to the spacing the primary arms of the dendrites. However, if tertiary arms are present, the spacing will be referred to this one once its smaller dimensions become more significant for the properties of the material, as discussed by Baptista et al. ${ }^{1,12}$. The microsegregation measurement initiates at the center of a dendritic arm and ends at the midpoint of the interdendritic region between adjacent arms, defining the microsegregation path, as shown in Figure 1.

About 40 concentration measurements were performed for each examined position along the entire die casting.

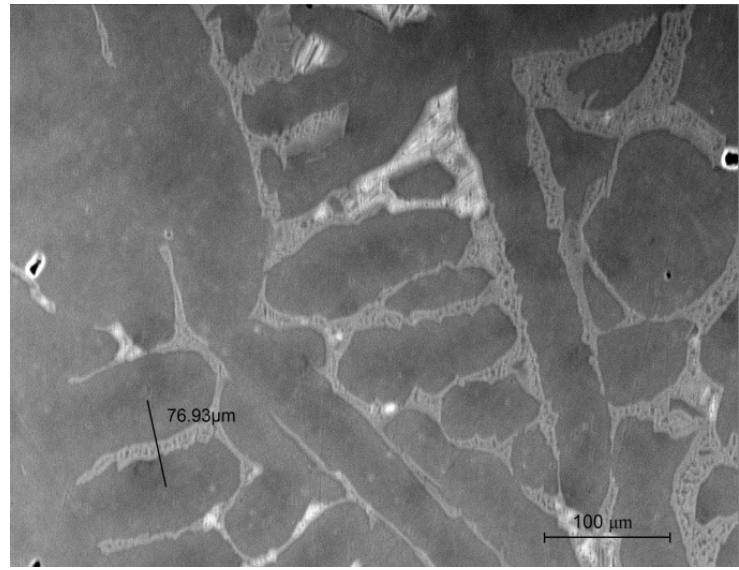

Figure 1. Typical track adopted for measurements of solute microsegregation of the $\mathrm{Cu}-20 \mathrm{wt} . \% \mathrm{Sn}$ alloy.

Table 1. Physical properties s $^{31,32,36}$.

\begin{tabular}{lc}
\hline \multicolumn{1}{c}{ Properties } & $\mathrm{Cu}-\mathrm{Sn}$ alloy \\
\hline Equilibrium partition coefficient, $\boldsymbol{k}_{e q}[-]$ & 0.34 \\
\hline Slope of liquidus line, $\boldsymbol{m}_{e}\left[\mathrm{~K} \mathrm{~mol}^{-1}\right]$ & 1129 \\
\hline Diffusivity in solid region, $\boldsymbol{D}_{\boldsymbol{s}}\left[\mathrm{m}^{2} \mathrm{~s}^{-1}\right]$ & $4.74 \times 10^{-13}$ \\
\hline Diffusivity in liquid region, $\boldsymbol{D}_{\boldsymbol{l}}\left[\mathrm{m}^{2} \mathrm{~s}^{-1}\right]$ & $3.23 \times 10^{-9}$ \\
\hline Diffusion layer thickness, $\delta[\mathrm{m}]$ & $4.4 \times 10^{-6}$ \\
\hline Molar volume, $\boldsymbol{V}_{\boldsymbol{m}}\left[\mathrm{m}^{3} \mathrm{~mol}^{-1}\right]$ & $9.48 \times 10^{-6}$ \\
\hline Liquidus temperature, $\boldsymbol{T}_{\boldsymbol{L}}[\mathrm{K}]$ & 1146 \\
\hline Interface energy, $\sigma\left[\mathrm{J} \mathrm{m}^{2}\right]$ & 1.29 \\
\hline
\end{tabular}

Physical properties adopted for this present work, were the same those used by Koheler et al. ${ }^{31}$, Kumoto et al. ${ }^{32}$ and calculated by Thermo-Calc Software ${ }^{36}$, Table 1.

\section{Results and Discussion}

Figure 2 shows the phase diagram of the $\mathrm{Cu}-\mathrm{Sn}$ alloy, calculated by thermodynamics software ${ }^{36}$. For $\mathrm{Cu}-20 \mathrm{wt}$. $\%$ Sn alloy, during cooling process the solidification begins at liquidus temperature of $873{ }^{\circ} \mathrm{C}$, as indicated in Figure 2, emphasizing the liquid-solid transformation region.

The solidification experiments focused on microsegregation phenomenon; the equilibrium partition coefficient is usually determined considering data from the equilibrium phase diagram. In present work, $k_{e q}=0.34$ corresponds to the concentration ratio between solid $\left(\boldsymbol{C}_{S}\right)$ and liquid $\left(\boldsymbol{C}_{L}\right)$ region, for alloy with initial concentration equal to $20 \mathrm{wt} \% \mathrm{Sn}$. The temperature profiles versus time experimentally determined during solidification are represented in Figure 3, for three specimens, which are denoted by 1, 2 and 3. Specimen 1 was extracted from cross section of casting, at $5 \mathrm{~mm}$ from the mold bottom, while specimens 2 and 3 were extracted at 10 and $15 \mathrm{~mm}$ from the mold bottom.

By using the data from temperature versus time (Figure 3) and the liquidus temperature, the position $(\boldsymbol{P})$ can be correlated with the time $(\boldsymbol{t})$ of passage of the liquidus isotherm by each position $(5,10$ and $15 \mathrm{~mm})$ in casting, thus permitting curves 


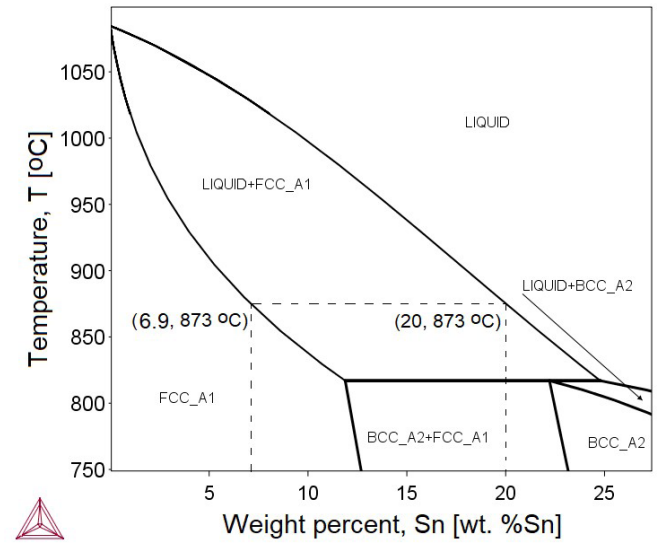

Figure 2. Binary phase diagram for the $\mathrm{Cu}-20 \mathrm{wt} . \% \mathrm{Sn}$ system calculated by Thermo-Calc Software ${ }^{36}$ with TCBIN database.

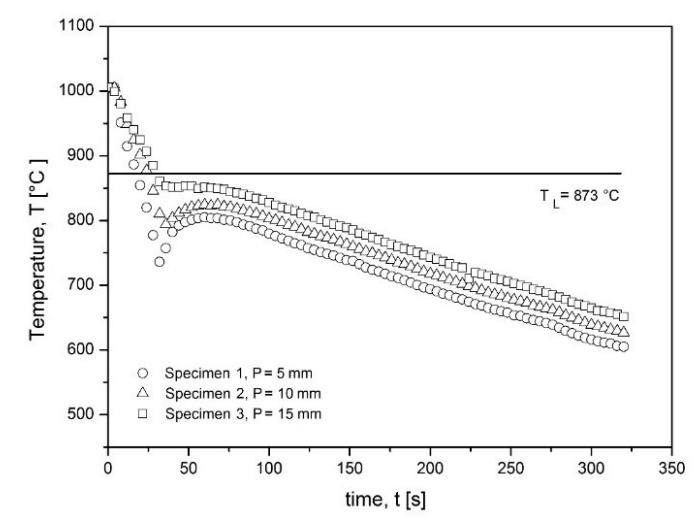

Figure 3. Temperature versus time.

$\boldsymbol{P}$ versus $\boldsymbol{t}$ to be plotted, as shown in Figure 4 (solid line). The derivative of the experimentally generated function with respect to time $(\boldsymbol{P}=\boldsymbol{f}(\boldsymbol{t}))$, permits the solidification growth to be calculated as a function of time, as also plotted in Figure 4 (dashed line).

In Figure 4, the solidification growth is seen to gradual decrease over time. This is due to the fact that the water-cooling system favors higher solidification growth at the beginning of solidification, which decreases along the experiment because of the increasing thermal resistance of the solidified region. From experimental equations $\left(P=f(t)\right.$ and $\left.S_{G}=f(t)\right)$ shown in Figure 4, it was possible to determine an equation for solidification growth as a function of position, Figure 5.

Figure 5 shows the magnitude modifications that occurred in the solidification growth values for the various positions along the casting length. Analyzing the experimental tendency in the graph of Figure 5, it can be inferred that the water-cooled system had significant impact on solidification growth. This means that high solidification growth was found in region close to the mold bottom. The relationship between cooling rate $(\dot{\boldsymbol{T}})$ and position $(\boldsymbol{P})$ is depicted in Figure 6.

It can be observed in Figure 6 , that cooling rate $(\dot{\boldsymbol{T}})$ decrease with position in casting, which is evidenced by the experimental law $\left(\dot{T}=52.40 P^{-0.95}\right)$. The said thermal parameter has been determined considering the temperatures versus time data immediately after the passage of the liquidus temperature for each position in the casting. The temperature data were collected at intervals of $0.001 \mathrm{~s}$, in order to permit

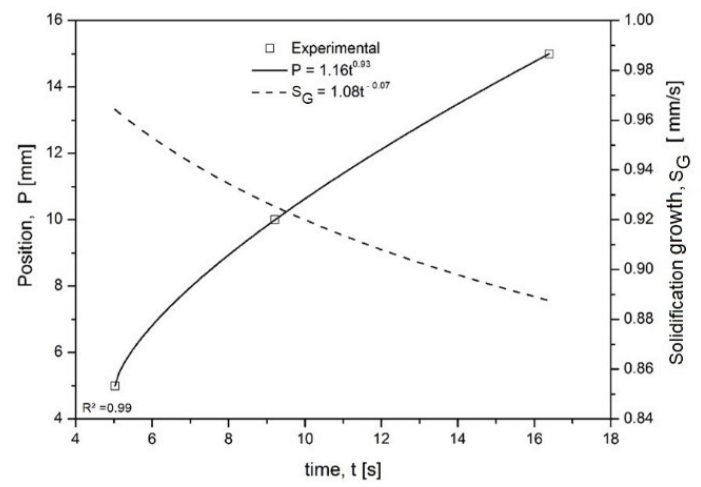

Figure 4. Position of liquidus temperature $(\boldsymbol{P})$ and solidification growth $\left(\boldsymbol{S}_{G}\right)$ versus time.

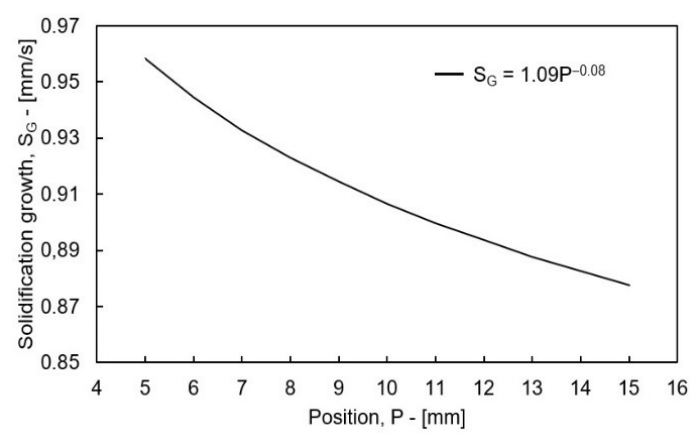

Figure 5. Solidification growth $\left(\boldsymbol{S}_{G}\right)$ as function of position $(\boldsymbol{P})$.

an accurate determination of the cooling rate. To investigate the effects of the solidification thermal parameter $(\dot{\boldsymbol{T}})$ on microstructural features and microsegregation, samples were taken from positions at 5, 10 and $15 \mathrm{~mm}$. A dendritic arrangement prevailed for all position considered, giving rise to well-defined tertiary dendritic arms $\left(\lambda_{3}\right)$ of the $\mathrm{Cu}-20 \mathrm{wt} . \%$ Sn alloy, as shown in Figure 7. The microstructure dendritic obtained during the solidification process, can be favored by high solidification speed, high initial concentration of solute in alloy and low thermal gradient. It is interesting to mention that work proposed by Valloton et al. ${ }^{37}$, the conditions adopted in solidification experiment favored a very low solidification speed, it can have affected the resulting microstructure. The said solidification speed observed in that work was $0.00058 \mathrm{~mm} / \mathrm{s}$ (ensuring planar front growth), while in present paper, we found a solidification speed between 0.88 to $0.96 \mathrm{~mm} / \mathrm{s}$. In such dendritic network, the tertiary dendritic arms play an important role, since they contribute for a more extensive distribution of $\mathrm{Sn}$ (microsegregation) throughout the microstructure.

It is important to highlight that $\dot{\boldsymbol{T}}$ and $\boldsymbol{S}_{G}$ will also have an important role, since they vary continuously with position, and may affect the microsegregation pattern between adjacent dendritic arms. At the left side of each photomicrographs in Figure 7, one can see information of specimen position in the casting $(\boldsymbol{P})$, cooling rate $(\dot{\boldsymbol{T}})$, tertiary dendritic arm spacing $\left(\lambda_{3}\right)$ and solidification growth $\left(\boldsymbol{S}_{G}\right)$. Tertiary dendritic arm spacing also depends strongly on the solidification growth, as discussed by Sales et al. ${ }^{5}$. The relationship between $\lambda_{3}$ and $\boldsymbol{S}_{G}$ is depicted in Figure 8.

Large dendritic variations were observed in present paper, the $\lambda_{3}$ varies significantly from 9.9 to $15.5 \mu \mathrm{m}$ in the 


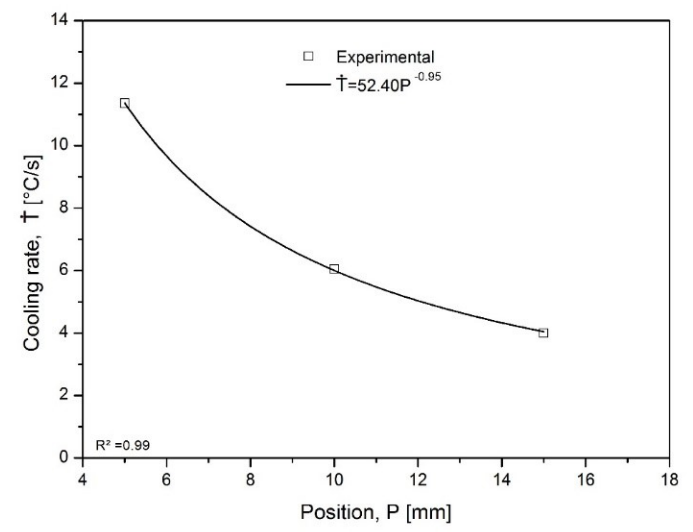

Figure 6. Cooling rate $(\dot{\boldsymbol{T}})$ versus position $(\boldsymbol{P})$.

$$
\begin{array}{r}
\boldsymbol{P}=5 \mathrm{~mm} \\
\boldsymbol{T}=11.4{ }^{\circ} \mathrm{C} / \mathrm{s} \\
\lambda_{3}=9.9 \mu \mathrm{m}
\end{array}
$$

$\mathbf{S}_{\mathrm{G}}=0.96 \mathrm{~mm} / \mathrm{s}$

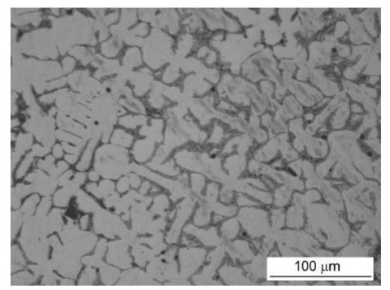

$$
\begin{array}{r}
\boldsymbol{P}=10 \mathrm{~mm} \\
\dot{\boldsymbol{T}}=6.1^{\circ} \mathrm{C} / \mathrm{s} \\
\lambda_{3}=11.9 \mu \mathrm{m} \\
\mathbf{S}_{\mathbf{G}}=0.91 \mathrm{~mm} / \mathrm{s}
\end{array}
$$

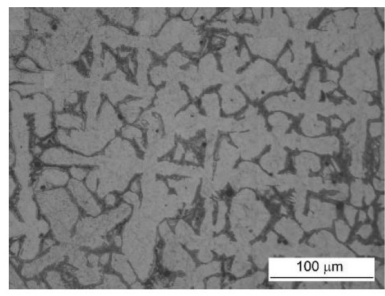

$$
\begin{gathered}
\boldsymbol{P}=15 \mathrm{~mm} \\
\dot{\boldsymbol{T}}=4.0{ }^{\circ} \mathrm{C} / \mathrm{s} \\
\lambda_{3}=15.5 \mu \mathrm{m}
\end{gathered}
$$$$
\mathbf{S}_{\mathbf{G}}=0.88 \mathrm{~mm} / \mathrm{s}
$$

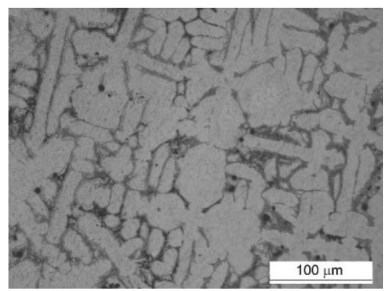

Figure 7. Photomicrographs of specimen taken from cross section of casting.

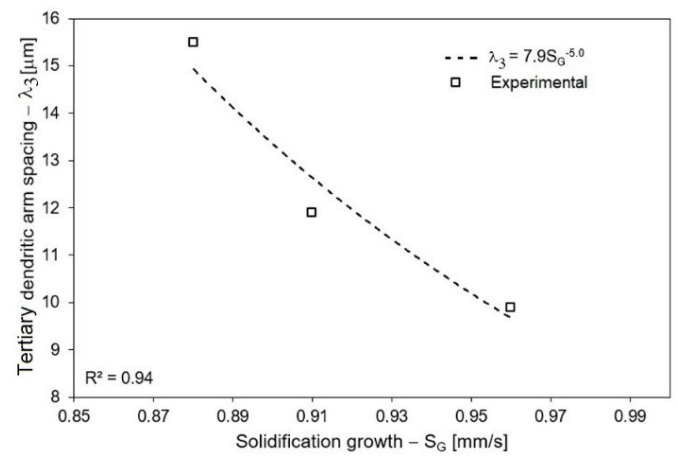

Figure 8. Tertiary dendritic arm spacing $\left(\lambda_{3}\right)$ versus solidification growth $\left(\boldsymbol{S}_{G}\right)$. specimens extracted along the length of casting. In the other hand, variations in $S_{G}$ from 0.88 to $0.96 \mathrm{~mm} / \mathrm{s}$ were found during the solidification experiment. It is worth noting that the $\lambda_{3}$ decreased with the $S_{G}$. The increase in the $S_{G}$ reduced the possibility of the dendritic growth in regions close to the mold bottom during the solidification experiment. Considering that solidification of commercial alloys occurs far from the equilibrium conditions, during simulation of solidification process, it is necessary to monitor the segregation under high solidification growth. Mathematical models using equilibrium partition coefficient $\left(\boldsymbol{k}_{e q}\right)$, may not adequately describe the behavior of solidification process. In order of improving the prediction capability of phase-field model considered in present work, the effective partition coefficient $\left(\boldsymbol{k}_{e f}\right)$ is determined. The Equation 10 has been used to create a plot of effective partition coefficient $\left(\boldsymbol{k}_{\boldsymbol{e f}}\right)$ versus solidification growth $\left(\boldsymbol{S}_{G}\right)$. In order to found an experimental equation of the effective partition coefficient $\left(\boldsymbol{k}_{e f}\right)$ as a function of solidification growth $\left(\boldsymbol{S}_{G}\right)$, a curve fitting technique have been adopted on points shown in Figure 9.

It is important to highlight that the experimental equation shown in Figure 9 have been determined for a solidification growth range from 0.88 to $0.96 \mathrm{~mm} / \mathrm{s}$ and that for higher solidification growth a tendency to approach $\boldsymbol{k}_{e f}=1$ will exist, since Equation 10 is operative between equilibrium partition coefficient $\left(\mathrm{k}_{\mathrm{eq}}=0.34\right)$ and 1 . In order to show the predictive capacity of this numerical technique, the results calculated by the phase-field model, was compared with those determined during solidification experiment. First of all, the values of solidification growth calculated by phase-field model and those obtained experimentally are shown in Figure 10. In both profiles, the $\boldsymbol{S}_{G}$ is seen to decrease faster at the onset of solidification. This rate then gradually diminishes towards completion of the solidification process. This slowing down in numerical profile of solidification growth, is due to a reduction of interface mobility $(\boldsymbol{M})$ as the solute concentration increases ahead of the solid/liquid interface. The microsegregation cannot be avoided during solidification since it is the result of the solubility difference between the liquid and solid phases. This segregation phenomenon is considered in phase-field model. The segregated solute from solid ahead of the solid/liquid interface affect significantly the solidification growth through phase-field mobility $(\boldsymbol{M})$ in Equation 5.

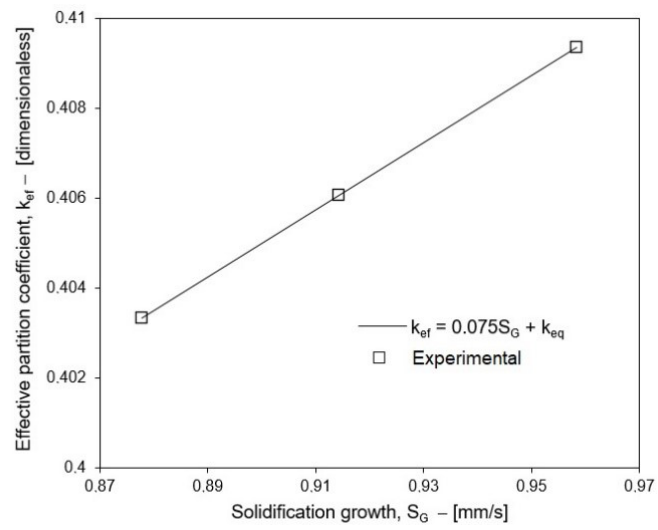

Figure 9. Effective partition coefficient $\left(\boldsymbol{k}_{e f}\right)$ versus solidification growth $\left(\boldsymbol{S}_{G}\right)$. 


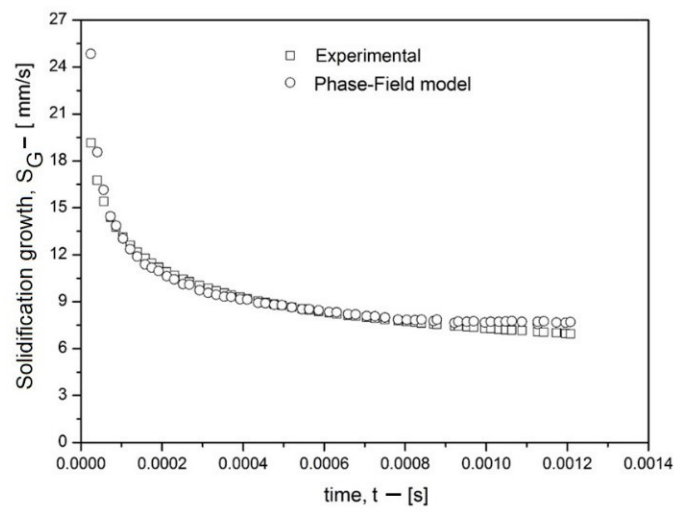

Figure 10. Comparison of solidification growth $\left(\boldsymbol{S}_{G}\right)$, as calculated via Phase-field model and experimental data.

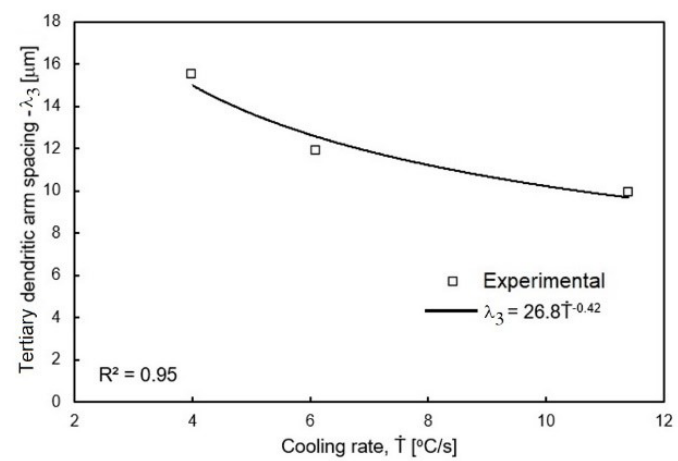

Figure 11. Tertiary dendritic arm spacing $\left(\lambda_{3}\right)$ versus cooling rate $(\dot{T})$.

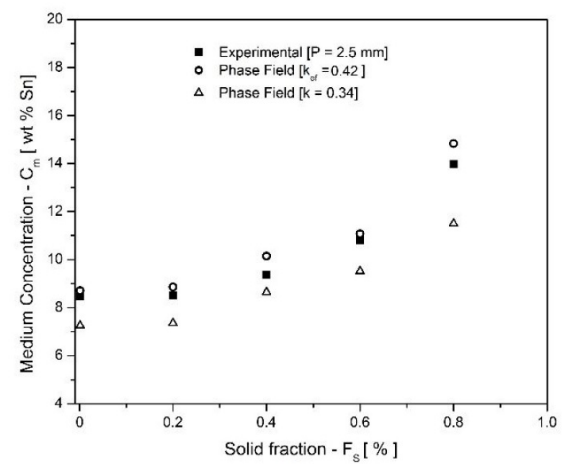

(a)

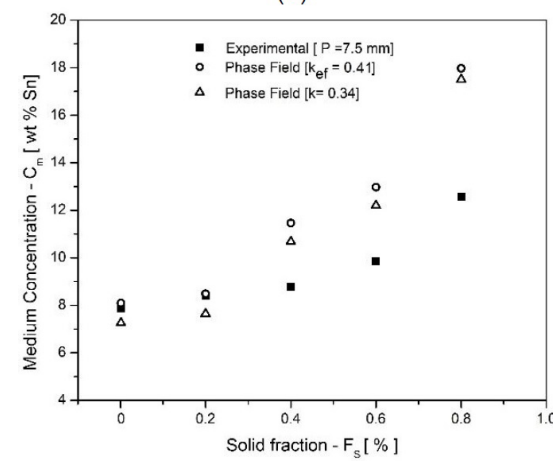

(c)
Results in Figure 10 display an excellent agreement between the numerical results and experimental of the solidification growth $\left(\boldsymbol{S}_{G}\right)$. But, as expected, the behavior is clearly nonlinear, with both profiles tending downwards as the time increases. To investigate the effect of cooling rate on the microstructure features of as-cast material, tertiary dendritic arm spacing determined along the casting are depicted in Figure 11.

The increase in cooling rate results in reduction of tertiary dendritic arm spacing, this takes place because tertiary-arm spacing depends on the competitive growth during solidification experiment. With higher cooling rates during the solidification experiment, temperature decays faster in liquid region ahead of the solid/liquid interface and the competitive growth between dendritic arms is more intense. Figure 12 exhibits a comparison of the Sn concentration as evaluated by phase-field model for the solid region with experimental results obtained in present work. One can see, in Figure 12a-d, that present-work based numerical results show good agreement with those obtained from experimental procedure. As expected, in any case examined it can be seen that the Sn concentration increase with solidified fraction. Microsegregation profiles were calculated via phase-field model with different values of effective partition coefficient $\left(\boldsymbol{k}_{e f}\right)$ and equilibrium partition coefficient $\left(\boldsymbol{k}_{e q}\right)$ at different positions in the casting. However, it seems that replacing $\boldsymbol{k}_{e q}$ by $\boldsymbol{k}_{e f}$ was not able to improve the predictive capacity of phase-field model, Figure 12b-d, with the exception of Figure 12a.

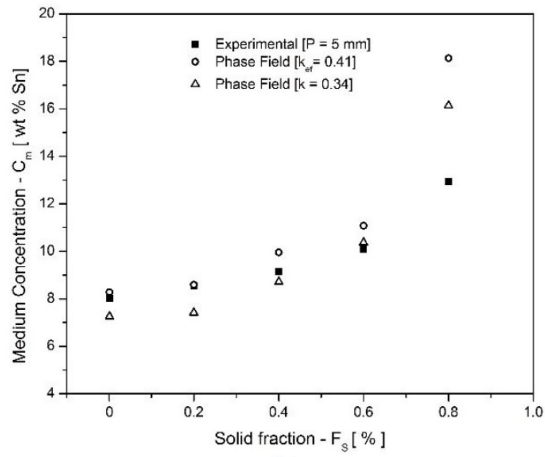

(b)

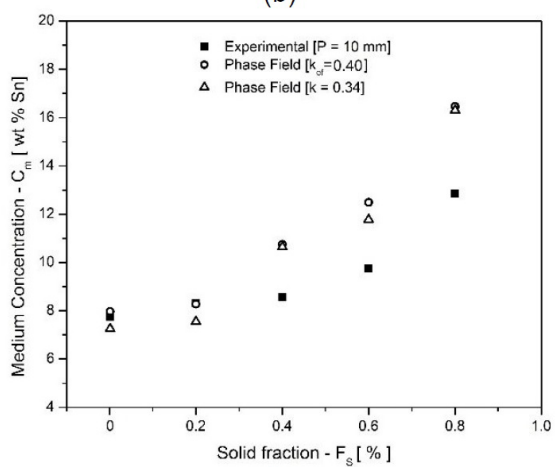

(d)

Figure 12. Microsegregation of Sn solute experimentally measured and calculated via phase-field model using the $\boldsymbol{k}_{e f}$ and $\boldsymbol{k}_{e q}$ at different positions along the casting: (a) $2.5 \mathrm{~mm}$ from the base bottom; (b) $5.0 \mathrm{~mm}$ from the base bottom; (c) $7.5 \mathrm{~mm}$ from the base bottom and, (d) $10 \mathrm{~mm}$ from the base bottom. 


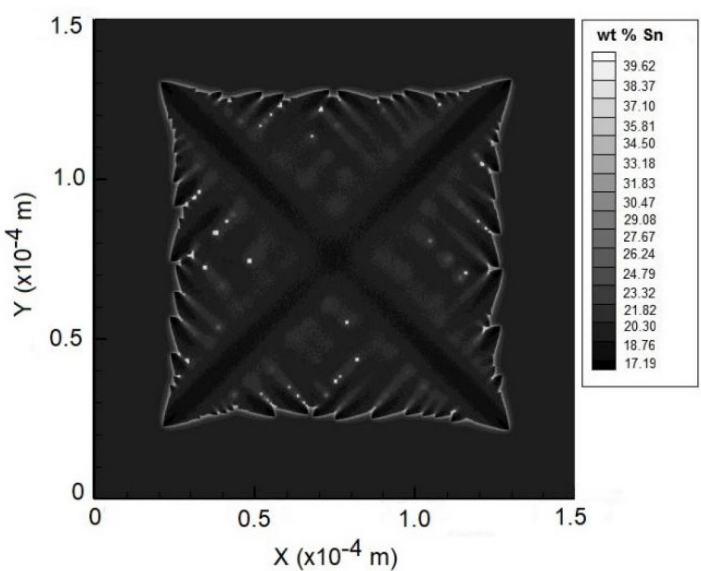

(a)

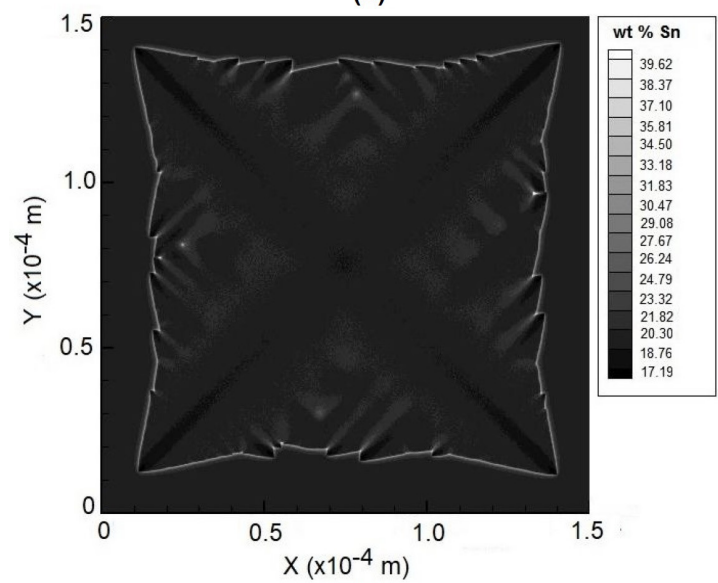

(b)

Figure 13. Dendrite shape with solidification time equal to $0.6 \times 10^{-2}$ s and different cooling rate: a) $\dot{\mathrm{T}}=5.1{ }^{\circ} \mathrm{C} / \mathrm{s} \mathrm{K}$ and, b) $\dot{\mathrm{T}}=6.2^{\circ} \mathrm{C} / \mathrm{s}$.

It is important to remark the nonlinear behavior in relationship between the $\mathrm{Sn}$ concentration and solid fraction. As discussed by Salvino et al. ${ }^{22}$, the phase-field model is able to calculate the back-diffusion during solidification, which represents the diffusion of Sn solute in the solid region. Figure 13 displays results obtained from microstructural simulation via phase-field model of a $\mathrm{Cu}-20$ wt.\% Sn alloy with solidification time of $0.6 \times 10^{-2} \mathrm{~s}$ and different cooling rates.

Figure 13a-b shows the morphology of dendrites which were calculated by phase-field model, for same Sn concentration and two different cooling rates, namely 5.1 and $6.2{ }^{\circ} \mathrm{C} / \mathrm{s}$. This figure shows similar microstructural features with those found in Figure 7. The increase in cooling rate at a fixed Sn concentration, results in change in size of dendrite. Secondary dendrite arm length suffered significant change, when a higher cooling rate was adopted in the simulation, Figure 13b. One can see that tertiary arms grew perpendicularly to the secondary arms. In the present calculation, solid/liquid interface motion is determined from the thermodynamic driving force, represented by the third term in Equation 1. The mobility of solid/liquid interface is favored during numerical simulation due to a decrease of the temperature in computational domain.

\section{Conclusions}

Regions closest to the mold bottom showed the highest cooling rate during the solidification experiment. This high value in said cooling rate are due to water-cooled system. In order to show the predictive capacity of phase-field model, the numerical results were compared with those obtained during solidification experiment. The values of numerical solidification growth and experimental were shown in Figure 10. In both cases, solidification growth $\left(\boldsymbol{S}_{G}\right)$ gradually diminishes towards completion of the solidification process. The decrease of the solidification growth $\left(\boldsymbol{S}_{G}\right)$ calculated by phase-field model is due to a reduction in interface mobility $(\boldsymbol{M})$. This, in turn, is affected by $\mathrm{Sn}$ segregated from the solid to the liquid region during the simulation of solidification process. Results in Figure 10 display an excellent agreement between the numerical results and experimental data of the solidification growth $\left(\boldsymbol{S}_{G}\right)$. But, as expected, the behavior is clearly nonlinear, with both profiles tending downwards as the time solidification increases. The increase in cooling rate favored a reduction in tertiary dendritic arm spacing, this takes place because dendritic arm spacing depends of its competitive growth during solidification process, Figure 11. As the cooling rate increases, system temperature decreases, and the competitive growth between tertiary arms becomes more intense. Profiles of Sn concentration calculated by phase-field model in solid region were compared with those experimental results. The present-work based numerical results show good agreement with experimental data. For any case considered, the $\mathrm{Sn}$ concentration increase with solidified fraction. Replacing $\boldsymbol{k}_{\boldsymbol{e q}}$ by $\boldsymbol{k}_{\boldsymbol{e}}$ in phase-field model, seems it was not able to improve the predictive capacity for regions far from water-cooled bottom, Figure 12b-d. The dendritic morphology as a function of cooling rate was investigated by phase-field model, Figure 13a-b. The numerical results showed that the size of dendrite is affected; in other words, secondary dendritic arm length suffered significant change, when a high cooling rate was considered during simulation of phase-field model.

\section{Acknowledgements}

The authors are grateful to FAPERJ (Fundação de Amparo à Pesquisa do Estado do Rio de Janeiro/APQ1: E-26/010.001942/2019) and CNPq (Conselho Nacional de Desenvolvimento Científico e Tecnológico) for financial support for developing this research.

\section{References}

1. Baptista LAS, Ferreira AF, Paradela KG, Silva DM, Castro JA. Experimental investigation of ternary Al-Si-Cu alloy solidified with unsteady-state heat flow conditions. Mater Res. 2018;21(3):e20170565. http://dx.doi.org/10.1590/1980-5373MR-2017-0565.

2. Goulart PR, Cruz KS, Spinelli JE, Ferreira IL, Cheung N, Garcia A. Cellular growth during transient directional solidification of hypoeutectic Al-Fe alloys. J Alloys Compd. 2009;470:589-99.

3. Silva AP, Spinelli JE, Garcia A. Microstructural evolution during upward and downward transient directional solidification of hypomonotectic and monotectic Al-bi alloys. J Alloys Compd. 2009;480:485-93.

4. Meza ES, Bertelli F, Goulart PR, Cheung N, Garcia A. The effect of the growth rate on microsegregation: experimental 
investigation in hypoeutectic $\mathrm{Al}-\mathrm{Fe}$ and $\mathrm{Al}-\mathrm{Cu}$ alloys directionally solidified. J Alloys Compd. 2013;561:193-200.

5. Sales RC, Junior PF, Paradela KG, Garção WJL, Ferreira AF. Effect of solidification processing parameters and silicon content on the dendritic spacing and hardness in hypoeutectic Al-Si alloys. Mater Res. 2018;21(6). http://dx.doi.org/10.1590/19805373-mr-2018-0333.

6. Monde AD, Chakraborty PR. Prediction of cooling curves for controlled unidirectional solidification under the influence of shrinkage: a semi-analytical approach. Metall Mater Trans, B, Process Metall Mater Proc Sci. 2018;49:3306-16.

7. Kaya H, Akerb A. Effect of alloying elements and growth rates on microstructure and mechanical properties in the directionally solidified Al-Si-X alloys. J Alloys Compd. 2017;694:145-54.

8. Desrosin W, Boycho L, Scheibera V, Méndez CM, Schvezov $\mathrm{CE}$, Ares AE. Evolution of metallographic parameters during horizontal unidirectional solidification of $\mathrm{Zn}-\mathrm{Sn}$ alloys. Procedia Materials Science. 2015;8:968-77.

9. Reinhart G, Gandin CA, Noel NM, Nguyen HT, Spinelli JE, Baruchel J, et al. Influence of natural convection during upward directional solidification: A comparison between in situ X-ray radiography and direct simulation of the grain structure. Acta Mater. 2013;61(13):4765-77.

10. Kim TB, Suzuki S, Nakajima H. Effect of conditions of unidirectional solidification on microstructure and pore morphology of Al-MgSi alloys. Mater Trans. 2010;51(3):496-502.

11. Boyuka U, Marasli N. Dependency of eutectic spacings and microhardness on the temperature gradient for directionally solidified $\mathrm{Sn}-\mathrm{Ag}-\mathrm{Cu}$ lead-free solder. Mater Chem Phys. 2010;119:442-8.

12. Baptista LAS, Paradela KG, Ferreira IL, Garcia A, Ferreira AF. Experimental study of the evolution of tertiary dendritic arms and microsegregation in directionally solidified $\mathrm{Al}-\mathrm{Si}-\mathrm{Cu}$ alloys castings. Journal of Materials Research and Technology. 2019;8(1):1515-21. http://dx.doi.org/10.1016/j.jmrt.2018.05.021.

13. Ferreira AF, Chrisóstimo WB, Sales RC, Garção WJL, Sousa NP. Effect of pouring temperature on microstructure and microsegregation of as-cast aluminum alloy. Int J Adv Manuf Technol. 2019;104:957-65. http://dx.doi.org/10.1007/s00170019-03979-6.

14. Gündüz M, Kaya H, Çardili E, Marasli N, Keslioglu K, Saatçi B. Effect of solidification processing parameters on the cellular spacings in the Al- $0.1 \mathrm{wt} \%$ Ti and Al- $0.5 \mathrm{wt} \%$ Ti alloys. J Alloys Compd. 2007;439:114-27.

15. Mardare CC, Hassel AH. Ultra-thin anodic alumina capacitor films for plastic electronics. Phys Status Solidi, A Appl Mater Sci. 2012;209:825-31.

16. Zhai W, Wang BJ, Lu XY, Wei B. Rapid solidification mechanism of highly undercooled ternary $\mathrm{Cu}_{40} \mathrm{Sn}_{45} \mathrm{Sb}_{15}$ alloy. Appl Phys, A Mater Sci Process. 2015;121:273-81.

17. Kazuhiro M, Takayuki H, Gen S, Osamu Y, Minoru K. Effects of $\mathrm{Ca}$ addition on solidification structure of $\mathrm{Cu}-\mathrm{Sn}-\mathrm{Zn}$ bronze castings. Mater Trans. 2007;48:799-806.

18. Battersby SE, Cochrane RF, Mullis AM. Microstructural evolution and growth velocity-undercooling relationships in the systems $\mathrm{Cu}, \mathrm{Cu}-\mathrm{O}$ and $\mathrm{Cu}-\mathrm{Sn}$ at high undercooling. J Mater Sci. 2000;35:1365-73.
19. Ferreira AF, Silva JA, Castro JA. Simulation of the solidification of pure nickel via the phase-field method. Mater Res. 2006;9(4):34956.

20. Wynblatt $P$, Landa A. Computer simulation of surface segregation in ternary alloys. Comput Mater Sci. 1999;15:250-63.

21. Ferreira AF, Olivé LF. Microsegregation in Fe-C-P ternary alloys using a phase-field model. J Braz Soc Mech Sci Eng. 2009;31(3):173-80.

22. Salvino IM, Olivé LF, Ferreira AF. Simulation of microsegregation in multicomponent alloys during solidification. Steel Res Int. 2012;83:723-32.

23. Salvino IM, Jácome PAD, Ferreira AF, Ferreira IL. An analysis of the physical properties of multicomponent alloys on the simulation of solidification by phase-field model. Mater Sci Forum. 2013;730-732:703-8.

24. Ferreira AF, Ferreira IL, Cunha JP, Salvino IM. Simulation of the microstructural evolution of pure material and alloys in an undercooled melt via phase-field method and adaptive computational domain. Mater Res. 2015;18(3):644-53.

25. Ode M, Kim SG, Kim WT, Suzuki T. Numerical prediction of the secondary dendrite arm spacing using a phase-field model. ISIJ Int. 2001;41(4):345-9.

26. Boettinger WJ, Warren JA, Beckermann C, Karma A. Phasefield simulation of solidification. Annu Rev Mater Res. 2002;32(1):163-94.

27. Ode M, Lee JS, Kim SG, Kim WT, Suzuki T. Phase-field model for solidification of ternary alloys. ISIJ Int. 2000;40(9):870-6.

28. Kim SG, Kim WT, Machiko JS, Suzuki T. Large scale simulation of dendritic growth in pure undercooled melt by phase-field model. ISIJ Int. 1999;39(4):335-40.

29. Kobayashi R. Modeling and numerical simulations of dendritic crystal growth. Physica D. 1993;63:410-23.

30. Wheeler AA, Murray BT, Schaefer RJ. Computation of dendrites using a phase field model. Physica D. 1993;66:243-62.

31. Kohler F, Campanella T, Nakanishi S, Rappaz M. Application of single pan thermal analysis to $\mathrm{Cu}-\mathrm{Sn}$ peritectic alloys. Acta Mater. 2008;56(7):1519-28.

32. Kumoto EA, Alhadeff RO, Martorano MA. Microsegregation and dendrite arm coarsening in tin bronze. Mater Sci Technol. 2002;18(9):1001-6.

33. Burton JA, Prim RC, Slichter WP. The distribution of solute in crystals grown from the melt. Part I. Theoretical. J Chem Phys. 1953;21:1987-90.

34. Chalmers B. (1964). Principles of solidification. New York: John Wiley \& Sons.

35. Paradela KG, Baptista LAS, Sales RC, Junior PF, Ferreira AF. Investigation of thermal parameters effects on the microstructure, microhardness and microsegregation of $\mathrm{Cu}-\mathrm{Sn}$ alloy directionally solidified under transient heat flow conditions. Mater Res. 2019;22(4). http://dx.doi.org/10.1590/1980-5373mr-2019-0259.

36. Thermo-Calc Software. Thermo-Calc Software AB. Sweden: Thermo-Calc Software; 2020.

37. Valloton J, Wagniere JD, Rappaz M. Competition of the primary and peritectic phases in hypoperitectic $\mathrm{Cu}-\mathrm{Sn}$ alloys solidified at low speed in a diffusive regime. Acta Mater. 2012;60:3840-8. 